\title{
Abstract \\ Evaluation of the Acute Flaccid Paralysis Surveillance System From 2016 to 2020: A Retrospective Study
}

\author{
Suhaib Abu Failat ${ }^{1}$, MD; Nabil Qasem ${ }^{1}$, MD; Majed Asad ${ }^{1}$, MD; Ibrahim Iblan ${ }^{2}$, MD; Ashraf Aqel ${ }^{1}$ \\ ${ }^{1}$ Jordan Ministry of Health, Amman, Jordan \\ ${ }^{2}$ Eastern Mediterranean Public Health Network, Amman, Jordan
}

\section{Corresponding Author:}

Suhaib Abu Failat, MD

Jordan Ministry of Health

ALhashimi Alshamaly, Basman Erea

Hay Naifah, Next to Prince Hamazah Hospital

Amman, 11118

Jordan

Phone: 96265200230

Fax: 96265688373

Email: s.abufailat@gmail.com

\section{Abstract}

Background: Acute flaccid paralysis surveillance played a major role in the global eradication of polio. The World Health Organization adopted this method to monitor the progress toward poliomyelitis eradication. The Expanded Program of Immunization in Jordan has routinely collected acute flaccid paralysis data since 1999, which then attained a polio-free certification. Yet, because of wars in neighboring countries such as Syria and Iraq, there is a risk of polio outbreaks occurring.

Objective: This study aims to evaluate the acute flaccid paralysis surveillance system in Jordan from 2016 to 2020 and identify areas for improvement.

Methods: This was a retrospective descriptive study that used data from the acute flaccid paralysis surveillance system in Jordan between January 2016 and December 2020. The World Health Organization standard indicators were used to evaluate the performance of the surveillance system.

Results: A total of 483 cases of nonpolio acute flaccid paralysis were reported. Most of them ( $\mathrm{n}=478,99 \%)$ were younger than 15 years, and among those, $55.6 \%$ were younger than 5 years, and 58\% were male. At the national level, the surveillance achieved all the World Health Organization indicators throughout the evaluating period, except for two indicators: the proportion of stool specimens from which nonpolio enterovirus was isolated in 2016 and 2017, and the nonpolio acute flaccid paralysis detection rate per 100,000 of the population younger than 15 years in 2020. At a subnational level (governorates level), the proportion of stool specimens from which nonpolio enterovirus was isolated, as an indicator, was not achieved most of the time. This was frequently observed in each of all evaluation years of 2016 to 2020. Moreover, most indicators were not achieved at the governorate level in 2020.

Conclusions: There are some gaps that need improvement in the acute flaccid paralysis surveillance system in Jordan, especially at the governorate level. The lower performance during 2020 could have been caused by the COVID-19 crisis and the lockdown during the pandemic. Similar challenges are possible in the future and proper preparation is required.

(iproc 2022;8(1):e36484) doi: $10.2196 / 36484$

\section{KEYWORDS}

acute flaccid paralysis; Jordan; surveillance system; polio; eradication 
Edited by Y Khader; this is a non-peer-reviewed article. Submitted 16.01.22; accepted 19.01.22; published 04.02.22.

Please cite as:

Abu Failat S, Qasem N, Asad M, Iblan I, Aqel A

Evaluation of the Acute Flaccid Paralysis Surveillance System From 2016 to 2020: A Retrospective Study iproc 2022;8(1):e36484

URL: https://www.iproc.org/2022/1/e36484

doi: $10.2196 / 36484$

PMID:

(C) Suhaib Abu Failat, Nabil Qasem, Majed Asad, Ibrahim Iblan, Ashraf Aqel. Originally published in Iproceedings (https://www.iproc.org), 04.02.2022. This is an open-access article distributed under the terms of the Creative Commons Attribution License (https://creativecommons.org/licenses/by/4.0/), which permits unrestricted use, distribution, and reproduction in any medium, provided the original work, first published in Iproceedings, is properly cited. The complete bibliographic information, a link to the original publication on https://www.iproc.org/, as well as this copyright and license information must be included. 